\title{
Absentee bidders and the declining price anomaly in wine auctions
}

\author{
Victor Ginsburgh*,**
}

October 1997

\begin{abstract}
The anomaly is concerned with the observation that in multiple-item auctions of identical objects, prices tend to decline over time. We show that in the case of wine auctions which have been analyzed frequently, the anomaly is likely to be caused by the fact that most bids are entered by absentees, who seem to use nonoptimal bidding strategies. Therefore, wine auctions can hardly be used to illustrate the standard multiple-object auction model.
\end{abstract}

Published Journal of Political Economy 106 (1998), 1302-1322.

\footnotetext{
* I am grateful to Christie's London wine department for having allowed me to access to some of their auctioneer's books and collect the data used in this paper. The conversations I had with Paul Bowker, Michael Broadbent and Duncan McEuen from Christie's London wine department on the functioning of wine auctions were very useful. Gian-Luigi Albano, Orley Ashenfelter, Claude d'Aspremont, Sherwin Rosen, Jonathan Shalev and Mary Sullivan made very useful comments on previous drafts. I am particularly grateful to a referee who forced me to look more carefully at my data. Support from the Centre Interuniversitaire pour les Etudes en Management (CIM), Brussels and from the John M. Olin Foundation, which made possible my visit to the University of Chicago, is gratefully acknowledged.

** Correspondence: Université Libre de Bruxelles, CP 139, 50 avenue F. Roosevelt, 1050 Brussels, Belgium.
} 


\section{Introduction}

An interesting overview of the behaviour of auctioneers and the atmosphere that is pervasive in many salerooms is provided by Smith (1989), who discusses several anomalies. One of these, the so-called declining price anomaly, was brought to the attention of a wider audience of economists by Ashenfelter (1989). The anomaly is concerned with the observation that in multiple-item auctions of identical objects, prices tend to decline over time.

The anomaly is reported to occur under various forms by Buccola (1982) for livestock auctions, Burns (1985) for wool auctions, Ashenfelter (1989), McAfee and Vincent (1993) and Di Vittorio and Ginsburgh (1994) for wines, Ashenfelter and Genesove (1992) for real estate, Beggs and Graddy (1996) for Impressionist and Modern paintings, Chanel, GérardVaret and Vincent (1996) for jewellery, Pesando and Shum (1996) for Picasso prints. Burns (1985) and Keser and Olson (1996) among many others have set up experiments and reach the same conclusion.

Several reasons, both theoretical and institutional, have been advocated to explain the anomaly. Ashenfelter (1989) suggests that risk aversion is at the root of the anomaly. McAfee and Vincent (1993) show that the more restrictive, and less likely, assumption of nondecreasing absolute risk aversion is needed for pure strategies to exist and for the result to hold. Beggs and Graddy (1996) show that if the quality of lots in a multi-object auction declines, the ratio "hammer price/pre-sale estimate" should also decline, even if bidders are risk neutral. For wine auctions, rules at Christie's provide that the (winning) buyer of the first lot "will, at the discretion of the auctioneer, have the option to take further lots of a similar bottle size [at the same price]."1 Black and de Meza (1993) and Burguet and Sakovics (1994) show that the uncertainty about future possibilities to buy that is introduced by this rule leads to declining prices. ${ }^{2}$

Burns (1985) argues that, in wool auctions, bidders are often agents who act for others and place higher bids than would be necessary to ensure them obtaining at least one of the items. This is close to the idea of buying to fill orders. Pesando and Shum (1996) observe that in multiple-item auctions of Picasso prints, salerooms consciously order the items by decreasing quality. If this were systematic, ${ }^{3}$ it could provide a ready explanation for the anomaly. To eliminate this possibility, Pesando and Shum look at identical prints sold in

\footnotetext{
1 See Christie's sales catalogues for wines.

2 Though Ashenfelter notes that in wine auctions, the winning bidder on the first lot has the option of taking any number of subsequent lots at the same price, this is not assumed in the McAfee-Vincent model.

3 Several departments at Christie's London confirm that this is the rule used in most cases.
} 
different auctions, but that occur sufficiently close in time (no more than 5 days apart). The number of cases is too small and the results provide no support for the anomaly.

Both Ashenfelter (1989) and McAfee and Vincent (1993) discuss wine auctions and confirm the existence of the declining price anomaly. The empirical tests conducted by Di Vittorio and Ginsburgh (1994), Beggs and Graddy (1996) and Chanel et al. (1996) need some qualification, since they measure the price decline in an indirect way. In all three cases, the authors deal with heterogeneous objects, which they homogenize by regressing prices on characteristics and, in some cases, on pre-sale estimates. The declining price anomaly is analyzed by introducing among the exogenous variables, an additional one which represents the order in which the item is auctioned. If prices ${ }^{4}$ decline, the coefficient picked by the "order in sale" variable should be negative. For wines, Di Vittorio and Ginsburgh (1994) find that the coefficient is indeed negative, but not significantly so. Beggs and Graddy (1996) report that both pre-sale estimates and prices relative to pre-sale estimates decline with order. Chanel et al. (1996) who deal with jewels sold at judiciary auctions, find that price behaviour for "identical" homogenized lots varies: Prices increase in the case of watches, decrease for objects in gold and are constant for other collectibles (bracelets, necklaces and rings). Ashenfelter and Genesove (1992) also proceed indirectly for their real estate auctions. They compare prices obtained at auction with those obtained in later face-to-face bargaining for identical condominium units. Prices decline as the auction progresses. This relation is not observed for units sold later on and can, therefore, not be due to declining quality, but to the auction mechanism itself.

\section{An analysis of wine auctions at Christie's London}

We now concentrate on wine auctions and show that the declining price anomaly is indeed observed, but is essentially due to the institutional functioning of auctions. We collected detailed data on four such sales held at Christie's in London in December 1995, January and February 1996. All four sales were held at King Street, where the better wines are usually sold. ${ }^{5}$ It is important to note that one of the sales is described as "remarkable" (February 22, Fine and Rare Wines), two others as featuring fine wines and vintage Ports (December 14, End of Year Fine Wines, and February 8, Fine Wines and Vintage Port), while the last one can probably be considered as relatively standard (January 25, Claret and White Bordeaux). ${ }^{6}$ Though the number of sales we study is probably too small to be considered as

\footnotetext{
4 Relative to pre-sale estimates in Beggs and Graddy (1996).

5 The more "standard" sales take place in rooms located in South Kensington.

6 Some details and the catalogue description are given in appendix.
} 
representative, ${ }^{7}$ the sample covers different situations and there is no reason to believe that attendance and bidding strategies during these auctions were very different from what they are in general.

There are three types of bidders: Those who attend the sale (in person or through an agent, sometimes a Christie's employee), those who bid on the telephone, ${ }^{8}$ and absentees who turn in written bids before the sale starts. Except in very rare cases, the auctioneer has the absentees' reservation prices registered in the so-called auctioneer's book and he bids on their behalf.

Table 1 provides a general overview of the four sales. Almost 3,000 lots came up and 86.4 percent were sold. ${ }^{9}$ Over 60 percent of the lots came in parcels, which, on average, contain 4.6 lots of one or several (dozens of) bottles. We will mainly be concerned with a detailed study of these 399 parcels (1,816 lots). ${ }^{10}$

All this is public information contained in the sales catalogues and price lists released after the auction. However, we also could access to the auctioneer's books which provide the reservation prices of the vendors, as well as the names (in fact, numbers) of the absentees together with their bids. The books also identify the winning bidder and the price at which he obtained the lot. ${ }^{11}$ This makes it possible to determine, lot by lot, whether there were written bids and who, whether present or absent, won the lot.

A summary of this information for parcels only is given in Table 2. It is immediately apparent that in the vast majority of cases, there are bids entered by absentees; in 3.2 percent of the cases (13), there was no written bid recorded and in 12.8 percent, the number of written bids $^{12}$ was smaller than the number of lots in a parcel. Therefore, the remaining 84 percent of the parcels would have been sold even with no one bidding from the room. ${ }^{13}$

Table 2 also illustrates the number of times prices for subsequent lots in a parcel increase, decrease or remain constant. The results show that the number of decreases is much

\footnotetext{
${ }^{7}$ Note that this is the same number as in McAfee and Vincent (1993).

8 Though this is rare for wines since the rule at Christie's is that telephone bids will not be accepted for lots under $£ 2,000$. There were no telephone bids during any of the four sales at which I was present.

9 The number of bottles sold is much larger since a lot may contain as much as five to ten dozens of bottles.

10 Note that similar wines may also be sold in different parcels and not sequentially. This will happen if the sellers are different. Such parcels may be considered by customers as being of different "quality," since they were stored in different cellars. We ignore these cases here; they are anyway not frequent.

11 Unfortunately, it does not provide information on the starting bid nor on the sequence of bids. This information is of course public and released during the auction, but is very difficult to keep track of without recording. And even so, it would often be hard to see whether the bid is made by the room or by the auctioneer acting for an absentee.

12 This takes into account that one bidder can bid for several lots; in several cases, there are less bidders than bids.

13 In all these cases, bids were higher than the lower bound of the range of the pre-sale estimate which, according to the rule set by Christie's, should be at least as large as the reservation price set by the seller.
} 
larger than the number of increases--and that some price decreases are substantial--, but also that prices are constant or move both up and down in half of the cases. We now turn to a more detailed analysis of the decreases by discussing four reasons for which declining prices are indeed observed, but may have little to do with auction theory: The reasons are essentially linked to the organization of wine auctions--though one may argue that wine auctions are organized that way because auctioneers have observed that prices decline. ${ }^{14} \mathrm{We}$ distinguish the option effect, the decreasing quality effect, the varying (size and) quantity effect and the absentee bidder effect.

\section{The option effect}

The first issue is the option offered to the winning bidder of the first lot (in a parcel) to buy, at the same price, any number of subsequent lots--as long as the size of the bottles in these lots is the same as in the first one. This is so at Christie's. Sotheby's seems even to extend this option to any winning bidder, and not only to the one who won the first lot. According to Ashenfelter (1989), there is no such option at Butterfield's San Francisco and declining prices are nevertheless observed. As already mentioned, this rule has been the subject of theoretical developments by Black and de Meza (1993) and Burguet and Sakovics (1994), but the intuition for its effect on prices is obvious: The price for the first lot is equal to later ones, plus a risk premium. However, if the option were unfrequently used, it would not be threatening. Table 2 shows that the option is exercised in more than 37 percent of the cases (much more frequently by absentees) and constitutes, therefore, a credible threat: Those who wait may not have the opportunity to buy any lot should the first buyer exercise his option.

Moreover, the fact that the option exists but is not exercised on all the lots signals that the price paid for the first lot is higher than the market clearing price. Therefore, the market clearing price will, on average, be higher in the cases where the option is exercised, and lower when it is not.

\footnotetext{
14 It is impossible to decide on this by just looking at auction results. Experiments, such as the ones run by Keser and Olson (1996) convey the feeling that declining prices can be generated under various experimental conditions.
} 


\section{The decreasing quality effect}

Secondly, prices may decline because lots are ordered by decreasing quality. ${ }^{15}$ Though, indeed, ordering by decreasing quality is the rule at Christie's, there are only 4 such cases. This is negligible and cannot provide an explanation for declining prices in wine auctions.

\section{The bottle size and quantity effects}

Thirdly, for many parcels with lots of identical wine and vintage, the number of bottles and their size vary across lots. Large bottles (magnums, double magnums, jeroboams and imperials) are often listed before standard $75 \mathrm{cl}$. ones. Wine connoisseurs claim that larger bottles make for better wines; 16 these are also less frequent than standard ones, and collectors may be willing to pay for rarity.

Moreover, the number of bottles of identical size offered in a lot often increases in later lots and standard demand theory would predict a decrease in the price per bottle. This is probably compounded by the fact that high transaction costs ${ }^{17}$ make it costly to resell any undesirable surplusses acquired if later (and usually larger) lots are bought.

In our calculations, we compute for each lot in a parcel a price per standard $75 \mathrm{cl}$. bottle. Therefore, if present, there could be a declining price effect that shows at breakpoints, i.e. when bottle size and/or number of bottles changes from one lot to the next. The number of such "breaks" is reported in Table 2, under the heading "quantity effect." It is observed in 44 cases and seems thus to be responsible for 24.5 percent of the total number of declines.

\section{The absentee bidder effect}

This is the fourth and probably most important observation. As can be seen from Table 3, in 60 percent of the parcels, all the lots were sold to absentees; this does not mean that there were no bidders in the room, but only that none of them could purchase a lot of this

15 The "fullness" characteristic of a bottle is said to influence quality, since the contact of wine with air should be minimal. "Ullage," as the seepage of wine from a bottle is called, results in different levels of fullness (from high-fill to below low shoulder). Condition is usually described in the sales catalogues.

16 Because of the porous nature of the cork, there is some exchange between the wine and air through the cork. Since there should be as little air-liquid contact as possible while a wine is ageing, one way to minimize this contact is to maximize the volume of liquid for a given amount of air-exposed surface-area. This can be achieved by using larger bottles. Consequently, one would expect this quality effect to be reflected in the price of larger bottles. Di Vittorio and Ginsburgh (1994) show that this is indeed the case: The price increase (for a standard $75 \mathrm{cl}$ volume) can be as large as $42 \%$ for imperials ( 8 bottles).

17 See e.g. Weil (1993). 
particular parcel. For another 30.8 percent, there was some competition between the room and absentees and finally, in 9.2 percent of the cases, only customers in the room entered bids that were high enough to buy all the lots in a parcel. We also observe that in 81.5 percent of the cases, the first winning lot goes to an absentee.

Though there may have been bidders present in the room competing, but unsuccesfully, with written bids, there is a strong indication that most wine sales, at least in London, are not attended by many bidders. For reasons that are unclear ${ }^{18}$--the relatively low value of the items is probably one of the explanations--, wine auctions often seem to deal with a large number of written bids, and this could obviously have an effect on the way the sale proceeds. In auctions for more expensive items, collectors use agents to bid on their behalf or bid themselves on the telephone. ${ }^{19}$ This helps bidders to capture the atmosphere of the sale (in particular, the number of bidders) and makes it possible for them to adapt their strategies.

Price decreases are observed 179 times. In 99 cases, they occur when only absentee bidders win; in $79(52+27)$ additional cases, both absentees and room bidders compete. ${ }^{20}$ Finally, there is one case only in which the declining price anomaly is observed and in which all the lots are knocked down for bidders attending the auction.

Some details on the organization of an (English and not sealed-bid) auction with written bids are useful at this stage. Written bids come in before the sale starts and are registered in the auctioneer's book who bids on behalf of absentees, who may enter their bids under various alternative forms:

Strategy 1: Quote a price for only one specific lot in the parcel;

Strategy 2: Quote different prices for several or all of the identical lots and instruct the auctioneer to stop bidding after having won one lot;

Strategy 2C: Same as strategy 2, except that prices quoted are equal;

Strategy 3: Quote different prices for several or all of the identical lots and instruct the auctioneer to stop bidding after having won several (a specified number of) lots;

Strategy 3C: Same as strategy 3, except that prices quoted are equal;

Strategy 4: Enter more complicated conditional bids, or state an upper limit for total expenditure; these forms are much less frequent and if they become too complicated (for instance, if the conditional bids are spread over various parcels), they are handled by a saleroom employee who bids from the room.

\footnotetext{
18 One of the reasons given by Christie's wine specialists is that the number of overseas clients is large.

19 I have seen a fairly large number of cases of art sales in which all the bids were entered exclusively by Christie's employees acting for telephone bidders.

${ }^{20}$ In 52 cases, the first lot goes to an absentee; in 27 cases to a bidder present in the room.
} 
The classical result on equilibrium bidding strategies in the case of multiple lots is due to Weber (1983) who derives bid functions under the assumptions that bidders are symmetric, risk neutral, have identically, independently distributed private values drawn from a uniform distribution with lower support of $\underline{v}$, and desire one unit each. In the case of second-price auctions, these functions are $b_{i}=\underline{v}+\left(v_{i}-\underline{v}\right)(n-k) /(n-s)$, where $b_{i}$ is the equilibrium bid of bidder $\mathrm{i}, \mathrm{vi}_{\mathrm{i}}$ is his private value, $\mathrm{n}, \mathrm{k}$ and $\mathrm{s}$ are respectively the number of bidders, the number of identical lots in a parcel and the order of the lot which is auctioned. These functions imply that the equilibrium bid should increase for each subsequent lot. It can then be shown that hammer prices should on average be equal. A similar result holds in the case of common values (instead of private values), while the affiliated values model even predicts steeper bidding functions. Nondecreasing absolute risk aversion produces declining prices, but is unlikely to prevail for wine auctions (values are relatively small), and would anyway lead to increasing bids. Therefore, one should expect absentees to bid for several lots, even if they wish to buy one lot only (Forms 2 and 3 above) and bids should be increasing with lot number. Though there exists no theoretical result for the case in which a bidder wishes to buy several units, intuition suggests that the strategies are likely to be similar. Of course, the theory implies that every bidder, whether in the room or absent, needs to know how many bidders will enter the game for each parcel; moreover the number of bids should larger than the number of lots, which is very often the case (see Table 2).

Observed bidding strategies, summarized in Table 4, are strikingly different from this theoretical prediction. In more than 90 percent of the cases in which there were written bids, these bids are constant, i. e. either strategy $2 \mathrm{C}$ or strategy $3 \mathrm{C}$ is followed, and the strategy predicted by theory (increasing bids) is followed in 3 cases only.

Therefore, if only absentees are interested and each of them sends a unique bid for (any) one or several lots in a parcel, it is obvious that the auctioneer will sell the lots to satisfy bids in decreasing order of value. A typical example is the following. In the sale of February 22, lots 479 to 481 each consisted of 12 bottles of Echézeaux 1988. Four written bids were registered, with each bidder willing to buy one lot at most. Bids were as follows: bidder no. 1006: $£ 500$; no. 1010: $£ 400$; no. 1013: $£ 340$ and no. 874: $£ 330$. The first lot went to bidder 1006 for $£ 360$, the second one to 1010 for $£ 350$ and the last one to 1013 for $£ 340.21$

\footnotetext{
21 When there is no supporting bidding in the room up to the levels set by absentees, these will often get the lot well below their bid. In this case, the fourth bidder at $£ 330$ did not win, the third got one lot at his bid value (£340), while the two others who entered bids of $£ 400$ and $£ 500$ respectively, were only charged $£ 350$ and $£ 360$. Note that this does is far from corresponding to a second price auction, since in that case, the highest bidder would have paid $£ 400$, the next one $£ 340$ and the last one $£ 330$. According to Christie's auctioneers, this "rule" prevents prices from "declining too much." This implies that hammer prices usually decline less rapidly than if a second price auction mechanism would be used. Note also that the auctioneer could have chosen to auction all three lots at $£ 340$, which would not have led to declining prices.
} 
If in the 99 cases mentioned earlier there is little or no competition at all from the room, this is a ready explanation for the declining price anomaly. If both absentees and bidders in the room compete (79 occurences), this effect may still be driving the result, especially in the 52 cases in which the first winning bid was placed by an absentee, who can have no feeling about what happens in the room during the auction.

A bidder who attends the sale has the possibility to gather information about the number of bidders for a specific parcel and thus compute his optimal strategy. This is of course impossible for absentees, and may turn out to be the reason for their apparently non optimal bidding behaviour. Moreover, there is a large number of cases in which absentees offer to buy several lots, a situation which is not analyzed (and seems vary hard to formalize) in auction theory. This also makes it impossible for absentees to infer how many lots remain unsold after each round, and thus the number of the lot that is auctioned ( $\mathrm{s}$ in the optimal bidding formula discussed earlier).

The "law of one price" could indeed said to be violated if declining prices were observed when all customers bid from the room, but this seems to happen very seldom. As shown in Table 5, all the lots in a parcel went to room-bidders in 37 cases, with 34 instances of constant prices (23 in which the the first winner exercised his option). This may well indicate that bidders in the room are likely to follow the strategy predicted by theory, so that, on average, realized prices are constant.

If the declining price anomaly were often observed with room-bidders, rational behaviour would make them all wait for the last lot. An obvious contradiction results. ${ }^{22}$

\section{Concluding comments}

In this paper, we show that declining prices are indeed observed in wine auctions. This "violates" the law of one price but for institutional reasons mainly. One could wonder why, knowing this, bidders do not show up more frequently at auction and are satisfied with sending in written bids.

Since identical wines come up for sale quite frequently, it is not very difficult to predict their prices, at least in the short run. Christie's wine department computes price indexes and may be using these to predict the pre-sale estimates published in their catalogues. Therefore, and with the exception of items that are collectibles, such as the bottle of Château d'Yquem

\footnotetext{
22 Note that bidders and auctioneers are aware of the difficulties and possible inconsistencies that appear when parcels are auctioned. See for example, a letter to the editor of the renowned wine review Decanter (May 1992, p. 7) "Fair bidding at auctions?" and the answer in the June 1992 issue by Michael Broadbent, Christie's wine specialist and auctioneer.
} 
1811 sold in the December 14 auction for $£ 14,000(\$ 21,000),{ }^{23}$ customers know with reasonable accuracy, how much a wine is worth and cannot be very much off when submitting written bids. For those cases in which prices do decline, the average decrease is equal to 10 percent. This represents $£ 2$ ( $\$ 3$ ) for a $£ 20$ bottle, or, for a twelve-bottle buyer, approximately the cost of cab-ride to and back from the auction room. At least in the case of wines, prices decline for very obvious (institutional) reasons. These cannot be invoked for auctions of other commodities, such as collectibles or real estate, where multiple-object parcels are rare, and where bidders are usually present at the auction.

It would be interesting to study why absentees use bidding strategies that do not conform with Weber's (1983) or similar models' theoretical predictions, which all yield increasing bids. One reason may be that they cannot use optimal bidding rules since they are unable to infer the number of bidders. Another reason may be linked to the fact that bidders are often willing to buy more than on lot of a parcel, a situation for which theoretical results seem to be particularly difficult to obtain.

23 Note that even for that case, the pre-sale estimate $(£ 15,000-20,000)$ was close to the hammer price. 


\section{References}

Ashenfelter, O. (1989), How auctions work for wine and art, Journal of Economic Perspectives 3, 23-36.

Ashenfelter, O. and D. Genesove (1992), Testing for price anomalies in real-estate auctions, American Economic Review 82, 501-505.

Beggs, A. and K. Graddy (1996), Declining values and the afternoon effect: Evidence from art auctions, manuscript.

Black, J. and D. de Meza (1993), Systematic price differences between successive auctions are no anomaly, Journal of Economics and Management Strategy 1, 607-628.

Buccola, S.T. (1982), Price trends at livestock auctions, American Journal of Agricultural Economics, 63-69.

Burguet, A. and J. Sakovics (1994), Sequential auctions with supply and demand uncertainty, Working Paper, Instituto de Analisis Economico, Barcelona.

Burns, P. (1985), Experience and decision making: A comparison of students and businessmen in a simulated progressive auction, Research in Experimental Economics 3, 139-157.

Chanel, O., L.-A. Gérard-Varet and S. Vincent (1996), Auction theory and practice: Evidence from the market for jewellery, in V. Ginsburgh and P.M. Menger, eds., Economics of the Arts. Selected Essays, Amsterdam: North Holland.

Di Vittorio, A. and V. Ginsburgh (1994), Pricing red wines of Médoc vintages from 1949 to 1989 at Christie's auctions, manuscript.

Keser, C. and M. Olson (1996), Experimental examination of the declining price anomaly, in V. Ginsburgh and P.M. Menger, eds., Economics of the Arts. Selected Essays, Amsterdam: North Holland.

McAfee, P. and D. Vincent (1993), The declining price anomaly, Journal of Economic Theory 60, 191-212.

Pesando, J.E. and P.M. Shum (1996), Price Anomalies at Auction: Evidence from the Market for Modern Prints, in V. Ginsburgh and P.M. Menger, eds., Economics of the Arts. Selected Essays, Amsterdam: North Holland.

Smith, C.W. (1989), Auctions. The Social Construction of Value, New York: The Free Press.

Weber, R.J. (1983), Multiple-object auctions, in R.E. Engelbrecht-Wiggans, M. Shubik and R. Stark, Auctions, Bidding and Contracting: Uses and Theory, New York: New York University Press.

Weil, R. (1993), Do not invest in wine, at least in the U.S. unless you plan to drink it, and maybe not even then, Paper presented at the 2nd International Conference of the Vineyard Data Quantification Society, Verona, February. 


\section{Appendix 1 Characteristics of the four wine auctions used in the paper}

The descriptions are taken from the sales catalogues.

1. December 14, 1995. 1078 lots for sale; 840 lots sold. ${ }^{24}$

End of Year Fine Wines. In the morning: Excellent vintage Port, mainly private cellars, vintages 1958 to 1987; fine Claret including an impériale of Latour 1961 and many top Châteaux of the sought-after 1982 and 1990 vintages; excellent Graves and Yquem; top-quality red Burgundy, including Grand Cru of the excellent 1978 vintage; fine white Burgundy; an excellent range of mixed stocks, including top-quality wines from a Swedish cellar, excellent Rhône; Loire; Alsace; rare Apostelwein; fine Hock and Mosel; Tokay; Napa Valley Cabernet and excellent Champagne. In the afternoon: Fine red and white Graves from Château Rahoul, including a range of formats; an impressive stock of wines, predominantly Claret and Sauternes, from a Continental cellar; excellent red and white Burgundy including mature wines for current drinking and a wide range of top wines from Leroy; venerable Cognac and other spirits, including rare Chartreuse.

2. January 25, 1996. 522 lots for sale; 483 lots sold. ${ }^{25}$

Claret and White Bordeaux.

3. February 8, 1996. 577 lots for sale; 493 lots sold. ${ }^{26}$

Fine Wines and Vintage Port. Excellent stock of vintage Port, incorporating many shippers of the 1963, 1970 and 1977 vintages; fine Claret, vintages 1928 to 1986, including excellent private stock of rare wines: Yquem of highly regarded vintages, substantial stocks of top-quality red and white Burgundy, incorporating many wines from top Domaines; excellent mixed stocks of fine wines, many from private cellars; a wide range of top-quality Rhône; excellent Champagne and venerable Brandy.

4. February 22, 1996. 770 lots for sale; 730 lots sold. ${ }^{27}$

Fine and Rare Wines from a Scandinavian Cellar. In the morning: An impressive range of Vintage Port, 1948 to 1985, also large parcels of Port from Fonseca for everyday drinking; excellent Claret, vintages 1970 to 1990, including many first-growths; a remarkable range of Le Pin; a wide range of Bordeaux from François Mitjaville; top-quality red and white Burgundy from excellent producers, including Domaine de la Romanée-Conti, Leroy and Comte Lafon; fine Rhône, including single vineyard Côte-Rôtie from Guigal and excellent champagne from Bollinger, Deutz and Pol Roger. In the afternoon: A remarkable range of excellent red and white Burgundy from the highly-regarded firm of Joseph Faiveley including a number of Grand Crus from the excellent 1988, 1989 and 1990 vintages as well as their rare Corton-Charlemagne; an impressive collection of small and mixed lots of fine and rare wines and venerable Brandy.

This sale is futher described as follows in Christie's Wine Department Sales Memorandum no. 362: [...] remarkable sale of Fine and Rare Wines [...] Remarkable not only for the size of the cellar as a singleowner collection, but also for the range and breadth of wines on offer. The wines included in this catalogue have been acquired over a period of time by a Scandinavian institution, and were impeccably stored under quite exceptional conditions in three purpose-built cellars, equipped with elaborate temperature and humidity controls. Two of the three cellars contained the majority of the cased stock, the third was fully racked and included all of these loose, buried wines. All wines featured in this sale were carefully checked and, where appropriate, packed over a period of three days by a team from Christie's Wine Department. The total consignment (in excess of 2,000 cases) was then loaded on two trailers for specialised transport to London, and is now lying under bond at Trapp Cellars [...].

24 The sale included one impériale of Château Latour 1961 (knocked down at £7,200) and one bottle of Château d'Yquem 1811 (£14,000)

25 The sale included 12 bottles of Château Petrus 1975 (£3,700).

26 The sale included several one bottle lots of Château Mouton-Rothschild 1961 ( $£ 1,900$ each).

27 The sale included 6 bottles of Château Latour 1961 (£3,600), 12 bottles of Château Le Pin 1982 (£11,000), 12 bottles of La Tâche $1978(£ 4,400)$ and several one-bottle lots of Romanée-Conti 1978 (£1,500 each). 
Table 1

General characteristics of the sales

(No. of cases and \%)

\begin{tabular}{lrrrrrr}
\hline & Dec. 14 & Jan. 25 & Feb. 8 & Feb. 22 & All & $\%$ \\
\hline No. of lots offered & 1,078 & 522 & 577 & 770 & 2,947 & 100.0 \\
$\quad$ Single lots & 382 & 309 & 183 & 257 & 1,131 & 38.4 \\
$\quad$ Lots in parcels & 696 & 213 & 394 & 513 & 1,816 & 61.6 \\
No. of lots sold & 840 & 483 & 493 & 730 & 2,546 & 86.4 \\
No. of parcels & & 54 & 86 & 117 & 399 & \\
No. of lots per parcel & 142 & 3.9 & 4.6 & 4.4 & 4.6 & \\
\hline
\end{tabular}

*In each of these parcels, at least two lots were sold.

Table 2

Characterizing bids on parcels

(No. of cases and \%)

\begin{tabular}{|c|c|c|c|c|c|c|}
\hline & Dec. 14 & Jan. 25 & Feb. 8 & Feb. 22 & All & $\%$ \\
\hline Total no. of cases & 142 & 54 & 86 & 117 & 399 & 100 \\
\hline No written bid & 9 & - & 1 & 3 & 13 & 3.2 \\
\hline Less written bids than lots & 20 & 4 & 15 & 12 & 51 & 12.8 \\
\hline More written bids than lots & 113 & 50 & 70 & 102 & 335 & 84.0 \\
\hline \multicolumn{7}{|l|}{ Price dynamics } \\
\hline Decreasing prices & 60 & 15 & 51 & 53 & 179 & 44.9 \\
\hline Increasing prices & 7 & 4 & - & 10 & 21 & 5.3 \\
\hline Both ways & 9 & 4 & 13 & 21 & 47 & 11.8 \\
\hline Constant prices & 66 & 31 & 22 & 33 & 152 & 38.1 \\
\hline \multicolumn{7}{|l|}{ Option } \\
\hline Exercised & 57 & 30 & 25 & 38 & 150 & 37.6 \\
\hline Not exercised & 85 & 24 & 61 & 79 & 249 & 62.4 \\
\hline Decreasing prices & 60 & 15 & 51 & 53 & 179 & 44.9 \\
\hline Due to quality effect & 1 & - & 3 & - & 4 & \\
\hline Due to quantity effect & 14 & 4 & 9 & 17 & 44 & \\
\hline Other & 45 & 11 & 39 & 36 & 131 & \\
\hline \multicolumn{7}{|l|}{ Price decreases $(\%)^{*}$} \\
\hline Average & 11.4 & 8.3 & 7.6 & 12.0 & 10.2 & \\
\hline Largest & 55.6 & 22.7 & 23.5 & 45.4 & 55.6 & \\
\hline
\end{tabular}

* Ratio of first (largest) to last (lowest) price in a parcel. 
Table 3

Detailed overview of the bids

(No. of cases and \%)

\begin{tabular}{|c|c|c|c|c|c|c|}
\hline & Dec. 14 & Jan. 25 & Feb. 8 & Feb. 22 & All & $\%$ \\
\hline Total no. of cases & 142 & 54 & 86 & 117 & 399 & 100 \\
\hline \multicolumn{7}{|l|}{ Cases with lots won by } \\
\hline Absentees only & 85 & 36 & 52 & 66 & 239 & 60.0 \\
\hline Room only & 18 & 4 & 4 & 11 & 37 & 9.2 \\
\hline Both & 39 & 14 & 30 & 40 & 123 & 30.8 \\
\hline \multicolumn{7}{|l|}{ First winning bid won by } \\
\hline Absentee & 111 & 44 & 74 & 96 & 325 & 81.5 \\
\hline Room & 31 & 10 & 12 & 21 & 74 & 18.5 \\
\hline Option exercised by & 57 & 30 & 25 & 38 & 150 & 37.6 \\
\hline Absentee & 47 & 26 & 20 & 32 & 125 & 31.3 \\
\hline Room & 10 & 4 & 5 & 6 & 25 & 6.3 \\
\hline Decreasing prices & 60 & 15 & 51 & 53 & 179 & 44.9 \\
\hline Absentees only & 33 & 9 & 29 & 28 & 99 & 24.8 \\
\hline Due to quality effect & 1 & - & 3 & - & 4 & \\
\hline Due to quantity effect & 8 & 3 & 4 & 8 & 23 & \\
\hline Other & 24 & 6 & 22 & 20 & 72 & \\
\hline Room only & - & - & 1 & - & 1 & 0.2 \\
\hline Other & - & - & 1 & - & 1 & \\
\hline Both & 27 & 6 & 21 & 25 & 79 & 19.8 \\
\hline Due to quantity effect & 6 & 1 & 5 & 9 & 21 & \\
\hline Other & 21 & 5 & 16 & 16 & 58 & \\
\hline Increasing prices & 7 & 4 & - & 10 & 21 & 5.3 \\
\hline Absentees only & 3 & 2 & - & 8 & 13 & \\
\hline Room only & 1 & - & - & 1 & 2 & \\
\hline Both & 3 & 2 & - & 1 & 6 & \\
\hline Both ways & 9 & 4 & 13 & 21 & 47 & 11.8 \\
\hline Absentees only & 3 & 2 & 6 & 7 & 18 & \\
\hline Room only & - & - & - & - & - & \\
\hline Both & 6 & 2 & 7 & 14 & 29 & \\
\hline Constant prices & 66 & 31 & 22 & 33 & 152 & 38.1 \\
\hline Absentees only & 48 & 23 & 18 & 27 & 116 & \\
\hline Room only & 15 & 4 & 2 & 6 & 27 & \\
\hline Both & 3 & 4 & 2 & - & 9 & \\
\hline
\end{tabular}


Table 4

Absentees' bidding strategies

(No. of cases and \%)

\begin{tabular}{|c|c|c|c|c|c|c|}
\hline & Dec. 14 & Jan. 25 & Feb. 8 & Feb. 22 & All & $\%$ \\
\hline Total no. of cases & 142 & 54 & 86 & 117 & 399 & 100 \\
\hline No written bid & 9 & - & 1 & 3 & 13 & 3.2 \\
\hline Strategy $2 C^{*}$ & 31 & 6 & 25 & 30 & 92 & 23.1 \\
\hline Strategy $3 C^{* *}$ & 91 & 44 & 50 & 75 & 260 & 65.2 \\
\hline Other strategies & 11 & 4 & 10 & 9 & 34 & 8.5 \\
\hline Incr. bids for identical quant. & - & - & 1 & 2 & 3 & \\
\hline Decr. bids for identical quant. & - & 3 & 6 & 1 & 10 & \\
\hline Diff. bids, but diff. quant. & 3 & - & 2 & 3 & 8 & \\
\hline Diff. bids, but diff. sizes & 7 & 1 & 1 & 3 & 12 & \\
\hline Decr. bids, but decr. quality & 1 & - & - & - & 1 & \\
\hline
\end{tabular}

* Quote equal prices for several of the identical lots and instruct the auctioneer to stop bidding after having won one lot.

** Quote equal prices for several of the identical lots and instruct the auctioneer to stop bidding after having won several (a specified number of) lots.

Table 5

Cases for which all lots in parcel

are obtained by room bidders

(No. of cases and \%)

\begin{tabular}{|c|c|c|c|c|c|c|}
\hline & Dec. 14 & Jan. 25 & Feb. 8 & Feb. 22 & All & $\%$ \\
\hline Total no. of cases & 18 & 4 & 4 & 11 & 37 & 100 \\
\hline No written bids & 9 & - & 1 & 3 & 13 & 35.1 \\
\hline Constant prices & 9 & - & 1 & 3 & 13 & 35.1 \\
\hline Decreasing prices & - & - & - & - & - & - \\
\hline Increasing prices & - & - & - & - & - & 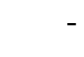 \\
\hline Written bids, but no winning one & 9 & 4 & 3 & 8 & 24 & 64.9 \\
\hline Constant prices & 8 & 4 & 2 & 7 & 21 & 56.8 \\
\hline Decreasing prices & - & - & 1 & - & 1 & 2.7 \\
\hline Increasing prices & 1 & - & - & 1 & 2 & 5.4 \\
\hline
\end{tabular}

